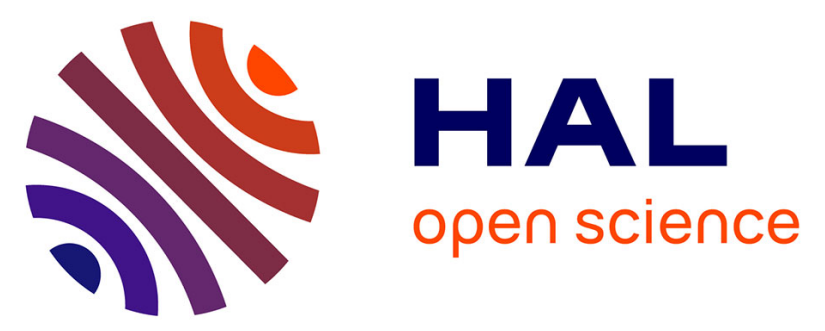

\title{
SATURATION OF RELAXATION ABSORPTION IN AMORPHOUS METALS AT VERY HIGH ACOUSTIC POWERS
}

\author{
W. Arnold, P. Doussineau, A. Levelut
}

\section{- To cite this version:}

W. Arnold, P. Doussineau, A. Levelut. SATURATION OF RELAXATION ABSORPTION IN AMORPHOUS METALS AT VERY HIGH ACOUSTIC POWERS. Journal de Physique Colloques, 1982, 43 (C9), pp.C9-553-C9-556. 10.1051/jphyscol:19829111 . jpa-00222416

\section{HAL Id: jpa-00222416 https://hal.science/jpa-00222416}

Submitted on 1 Jan 1982

HAL is a multi-disciplinary open access archive for the deposit and dissemination of scientific research documents, whether they are published or not. The documents may come from teaching and research institutions in France or abroad, or from public or private research centers.
L'archive ouverte pluridisciplinaire HAL, est destinée au dépôt et à la diffusion de documents scientifiques de niveau recherche, publiés ou non, émanant des établissements d'enseignement et de recherche français ou étrangers, des laboratoires publics ou privés. 


\title{
SATURATION OF RELAXATION ABSORPTION IN AMORPHOUS METALS AT VERY HIGH
}

\section{ACOUSTIC POWERS}

\author{
W. Arnold $d^{*}, P$. Doussineaut ${ }^{* *}$ and A. Levelut ${ }^{* *}$ \\ * Frounhofer-institute for Non-Destmutive Testing, BIdg 37, University, \\ 6600 Saarbruecken 11, F.R.G. \\ ** Laboratoire d'Ultrasons ${ }^{(+)}$, Univexsité Pierre et Marie Curie, Tour 13, \\ 4 Place Jussieu, 75230 Paris Cedex 05, France
}

\begin{abstract}
Résumé. - Une explication est proposée pour les effets non-linéaires récemment observés sur l'atténuation ultrasonore de PdSicu amorphe et quelques autres métaux amorphes. Ces effets sont attribués à la saturation de l'atténuation de relaxation lorsque le flux acoustique est suffisamment intense pour égaliser la population des systèmes à deux niveaux dont les énergies s'étendent jusqu'à k'T.
\end{abstract}

\begin{abstract}
. - strong non-linear effects recently observed in the acoustic absorption in amorphous PdSiCu and other amorphous metals are explained. We propose that saturation of the relaxation absorption due to tunneling sites might occur, when the acoustic power becomes so large that the whole ensemble of two level systems (TLS) is saturated up to energy splittings of the order of $\mathrm{kT}$.
\end{abstract}

Amorphous metals and insulators contain low-energy excitations which determine to a large extent their low-temperature behaviour, in particular specific heat, thermal conductivity, acoustic absorption and dispersion [1]. These low-energy excitations are ascribed to tunneling sites, also known as two level systems (TLS) inherent in the amorphous structure $[2,3]$. Their distinct feature is an almost constant density of states over a wide energy range, at least up to a few $K$. The acoustic behaviour of these materials is mainly determined by two processes due to TLS [4]. In the resonant absorption, only TLS are participating whose energy splittings $E$ match the energy of the ultrasonic phonon within the bandwidth $\hbar \Gamma_{2}=\hbar / T_{2}$. Here, $\mathrm{T}_{2}$ is the transverse relaxation time of the TLS. This absorption becomes powerdependent when the acoustic flux exceeds a certain critical value $\phi_{c}$ at which the decay rate $\Gamma_{1}=1 / T_{1}\left(T_{1}\right.$ is the longitudinal relaxation time) of the TLS taking part becomes smaller than the absorption rate. In contrast, in the relaxational absorption process all TLS take part which are thermally excited and hence all TLS with energy splittings $E$ up to a few $\mathrm{kT}$. The time varying acoustic strains modulates $\mathrm{E}$ and absorption arises because the TLS return to equilibrium out of phase with the acoustic wave [4]. Of course both absorption mechanisms also contribute to dispersion, and in fact, are the only important dispersion mechanisms in amorphous materials at low temperatures. In amorphous metals, the TLS not only couple to phonons, but also to electrons thus dominating $\Gamma_{1}$ [5]. This in turn leads to a drastic increase of the critical intensity $\phi_{c}$ by four orders of magnitude compared to amorphous insulators.

Recently, a number of experiments have been reported $[6,7]$ which indicated an hitherto unknown power-dependent absorption mechanism due to TLS. It can be described by the following empirical formula :

$$
\alpha^{\prime}=\alpha_{0}^{\prime}\left(1+\phi / \phi_{c}^{\prime}\right)^{-1 / 2}
$$

Here, $\phi$ is the acoustic flux, and $\phi_{c}^{\prime}$ is the acoustic flux above which this effect

(t) Associated with the Centre National de la Recherche Scientifique. 
becomes noticeable. $\alpha_{0}^{\prime}$ is very weakly temperature dependent. Strinkingly, the power dependence resembles the one for the resonant absorption :

$$
\alpha_{\text {res }}=\alpha_{0}\left(1+\phi / \phi_{C}\right)^{-1 / 2} ; \alpha_{0}=\frac{\pi}{\rho \overline{\mathrm{P}}^{2} \omega} \mathrm{v}^{3} \tanh \left(\frac{\hbar \omega}{2 \mathrm{kT}}\right)
$$

Here, $\omega / 2 \pi$ is the sound frequency, $\rho$ is the density, $v$ is the sound velocity, $\bar{p}$ is the density of states, and $\gamma$ is the deformation potential TLS-phonons. $\phi_{\mathrm{C}}=\hbar^{2} \rho \mathrm{v}^{3} /\left(2 \gamma^{2} \mathrm{~T}_{1} \mathrm{~T}_{2}\right)$ is the critical flux for saturation of the resonant absorption [1]. If we would try to identify the observed nonlinear absorption with a resonant absorption process using equation (2), this would yield a far too large $\bar{p}_{\gamma}{ }^{2}$. On the other hand, $a_{0}^{i}$ corresponds in magnitude to the relaxational absorption. Experimental$1 \mathrm{y}$, this situation has been partially clarified very recently [8] by showing that two power-dependent absorption mechanisms do exist in a-PdSiCu. One corresponds to the already, known saturable resonant absorption and is fully described by equation (2). Since $\alpha_{0}^{\prime} \sim \alpha_{\text {rel }}$, and because of the observed power dependence of $\alpha^{\prime}$, one is tempted to devise a mechanism which could lead to saturation of the relaxation absorption hitherto unknown. We shall show that such a mechanism can exist and, in fact, explains the experimental findings quite well.

As already mentioned above, resonant absorption occurs over a bandwidth of the order of $\Gamma_{2}$. However, with increasing acoustic power the spectrum of TLS which couple to the oscillating acoustic strain increases. This power dependent bandwidth can be expressed as [9] :

$$
r_{2}^{\prime}=\Gamma_{2}\left(1+\phi / \phi_{c}\right)^{1 / 2}
$$

We might expect saturation of the relaxational absorption when an appreciable number of TLS taking part in this process are affected by the sound wave. Since all thermally excited TLS are participating in the relaxation process, $\Gamma_{2}^{r}$ should then be of the order of $\mathrm{kT} / \mathrm{h}$. From equation (3) and with $\mathrm{T} \sim 1 \mathrm{~K}$ (at which the experiments were indeed carried out) we estimate $\phi / \phi_{C} \approx 10^{2}$ assuming $T_{2}=2 T_{1}=10^{-10} \mathrm{sec}$. Furthermore, since $\phi=\frac{1}{2} \rho \mathrm{v}^{3} \mathrm{~S}^{2}$ an acoustic strain $\mathrm{S}$ of the ordex of $10^{-4}$ is obtained. Such high strain values, however, were indeed applied in the experiments reported recently $[6,7,8]$, and thus encourage this approach in order to further investigate its consequences.

Saturation phenomena play an important rôle in spin resonance as well as optical resonance. There exists a wealth of theoretical approaches to describe saturation of an ensemble of two state systems, supported by a large number of experiments. But indeed a complete and rigorous treatment of all relevant nonlinear effects do not exist. Therefore, we are reduced to assume a reasonable hypothesis: because of saturation, the longitudinal susceptibility which is the fundamental quantity is multiplied by a factor $w$ :

$$
\mathrm{w}=\frac{\Gamma_{2}^{2}+\omega_{0}^{2}}{\omega_{0}^{2}+\Gamma_{2}^{2}\left(1+\phi / \phi_{c}\right)}
$$

where the energy splitting $E$ of the TLS is $n \omega_{0}$. Using Eq. (4) we then obtain for the relaxation attenuation:

$$
\alpha_{r e 1}=\frac{2 \omega C}{v} \int d \omega_{0} \frac{\hbar}{4 k T} \operatorname{sech}^{2}\left(\frac{\hbar \omega_{0}}{2 k T}\right) \int d r \frac{\sqrt{1-r}}{r} \frac{\omega T_{1}}{1+\omega^{2} T_{1}^{2}} \frac{\omega_{0}^{2}+\Gamma_{2}^{2}}{\omega_{0}^{2}+\Gamma_{2}^{2}\left(1+\phi / \phi_{C}\right)}
$$

It should be noted that equation (5) contains the distribution of relaxation strength according to the tunneling model, and in order to be consistent, this distribution also has to be invoked in w (equation (4)). We now calculate $\alpha_{\text {rel }}$ using $\mathrm{T}_{2}=2 \mathrm{~T}_{1}$, and adding the resonant absorption according to equation (2). We then obtain the solid curve in figure 1. As can be seen, there is quite good agreement with the experiment (open circles). Also the other main features of the experiment can be explained, and we mention only two :

a) The weak temperature dependence of $\alpha_{0}^{\prime}$ : keeping in mind that an upper limit $\phi_{\mathrm{u}}$ of acoustic power is applied in the experiment, we write $\alpha^{\top}=\alpha_{r e l}(T, \phi \rightarrow 0)-\alpha_{r e l}\left(T, \phi_{U}\right)$. This procedure is an oversimplified schema for the analysis in $[6,7,8]$ which used an extrapolation out of the experimentally explored domain of acoustic power. However, in spite of the crudeness of our procedure we 


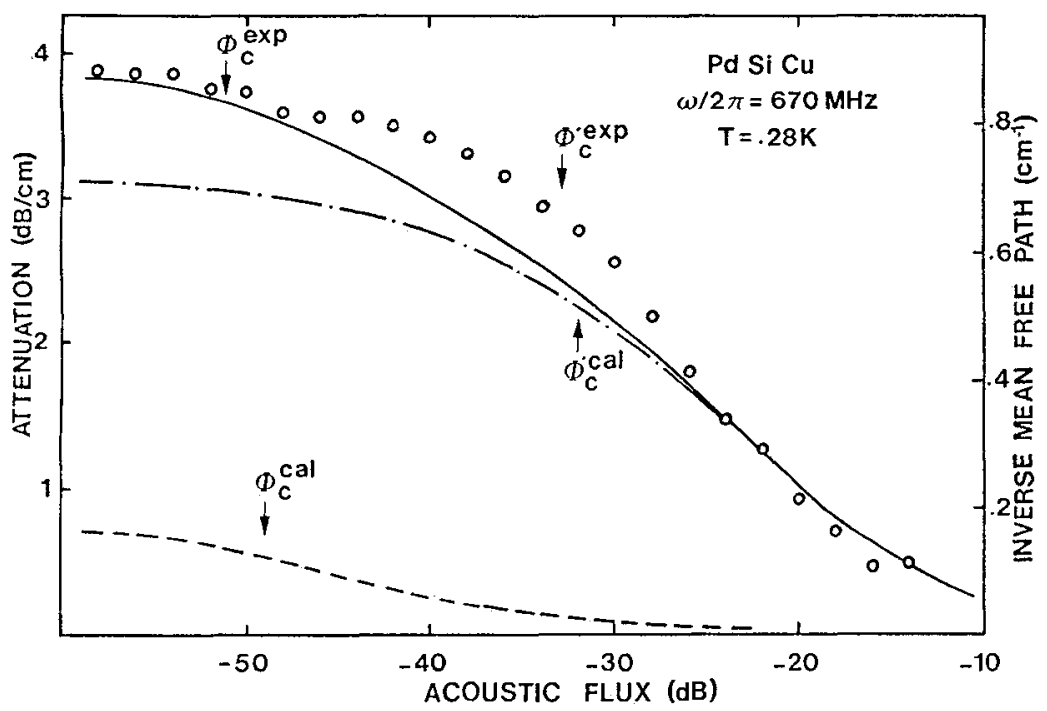

Figure 1. Power-dependent absorption in the amorphous metal Pasicu for a frequency of $670 \mathrm{MHz}$ and a temperature of $0.28 \mathrm{~K}$. Theoretical results are represented by the solid line, and experimental points by the open circles [8]. The theoretical calculation is the sum of the resonant absorption (dashed line) and the power-dependent relaxation absorption (dashed-dotted line). $\phi_{\mathrm{Cxp}}^{\exp } \phi_{\mathrm{C}}^{\prime} \exp$ are experimental values from reference [8]. $\phi_{C}^{c a l}$ and $\phi_{C}^{c}$ cal are the values calculated as explained in the text.

achieve quite good agreement with the results given in [8].

b) The effect was not observed in fused silica at $0.3 \mathrm{~K}$ [6]. This follows straightforwardly from the fact that in amorphous insulators $\alpha_{\text {rel }}$ has then vanished almost completely $\left(a_{\mathrm{re}} \sim 0.06 \mathrm{~dB} / \mathrm{cm}\right.$ at $\left.\mathrm{T}=0.3 \mathrm{~K}\right)$. In contrast, in a-metal $\alpha_{\mathrm{re}}$ decreases less rapidly because it is mostly governed by electrons and not by phonons. However, also in a-metals $\alpha_{\text {rel }}$ should tend to zero at $\mathrm{mk}$ temperatures. Finally, we should like to mention that according to our model the sound velocity change caused by relaxation also becomes saturable, but we shall present corresponding calculations in a more detailed paper.

In summary, we have proposed an explanation for the non linear relaxation absorption observed in amorphous metals. Our model is based on saturation of the TLS ensemble over a spectral width of the order of $\mathrm{kT} / \mathrm{h}$.

Acknowledgement : One of us (W. A.) thanks the Fraunhofer-Institute at Saarbruecken for the use of its computer facilities.

\section{References}

[1] For a recent review see collected papers "Amorphous Solids", edited by W. A. Phillips (Springer, 1981).

[2] ANDERSON P. W., HALPERIN B. I., and VARMA C., Phil. Mag. 25 (1972) 1.

[3] PHILIIPS W. A., J. Low Temp. 7 (1972) 351.

[4] See for example, JÄCKLE J., PICHE L., ARNOLD W., and HUNKLINGER S., J. Non Cryst. Sol. 20 (1976) 365.

[5] GOLDING B., GRAEBNER J. E., KANE A. B., and BLACK J. I., Phys. Rev. Lett. 41 (1980) 1487. 
[6] ARAKi h., PARK G., HikATA A., and Elbaum C., Sol. St. Comm. 32 (1979) 625 ; Phys. Rev. B 21 (1980) 4470 .

[7] park G., hikata A., and elbaum C., J. Non Cryst. Sol. 45 (1981) 93 ;

Phys. Rev. B 23 (1981) 5597 ; Phys. Rev. B 24 (1981) 7389.

[8] HIKATA A., CTBUZAR G., and ELBAUM C., unpublished.

[9] ALLEN I., and EBERLY J. H., Optical Resonance and Two-level Atoms (Wiley, 1975). 